\title{
Prediction of Geometry of Pulsed GMAW Fillet WELDED JOINTS OF STRUCTURAL STEELS
}

\author{
Petar Tasic, Ismar Hajro, Damir Hodzic \& Adi Pandzic
}
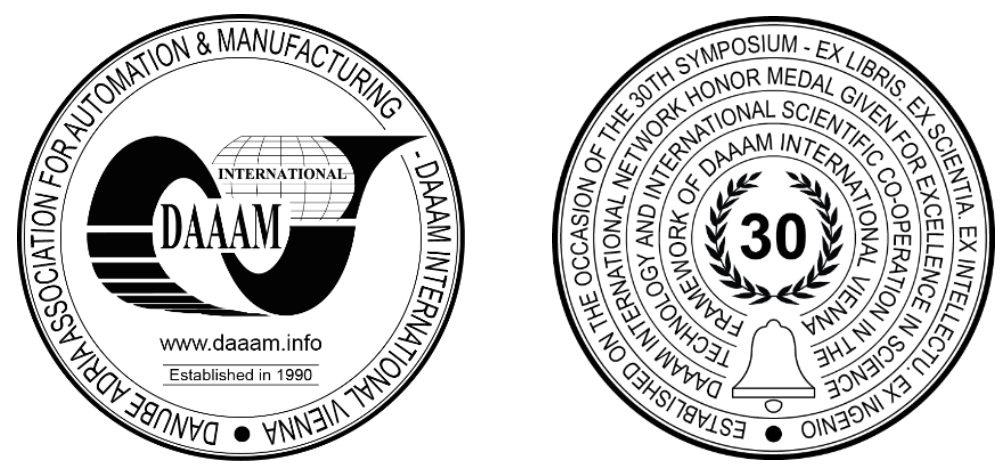

This Publication has to be referred as: Tasic, P[etar]; Hajro, I[smar]; Hodzic, D[amir] \& Pandzic, A[di] (2020). Prediction of Geometry of Pulsed GMAW Fillet Welded Joints of Structural Steels, Proceedings of the 31st DAAAM International Symposium, pp.0444-0452, B. Katalinic (Ed.), Published by DAAAM International, ISBN 978-3-90273429-7, ISSN 1726-9679, Vienna, Austria

DOI: $10.2507 / 31$ st.daaam.proceedings.062

\begin{abstract}
Gas Metal Arc Welding (GMAW) is nowadays widely used welding process for structural steels. It is highly efficient and can be easily automatized. Therefore, GMAW is particularly useful for welding of long sections in shop-floor conditions. Such components are prefabricated parts of ship hulls and bridges and parts of heavy machinery. Pulsed variant of GMAW is even more productive and efficient regarding use of filler material and welding time, often used as fully automatized or robotic process. However, such significant production rate requires efficient quality control of welds. The simplest way to do it is by visual inspection, which includes acquiring weld geometry and dimensions. That can be easily done by using optical measuring devices and cameras, which acquire necessary data directly after welding. However, this way of quality and process control needs relationship(s) between input (welding parameters and heat input) and output (weld geometry and dimensions). This paper presents principal relations between abovementioned inputs and outputs for single-pass fillet welds of structural steels. Considered output includes geometrical properties (fillet weld size, penetration, dilution, and reinforcement), while relations are described with fitting curves based on linear regression.
\end{abstract}

Keywords: GMAW; pulsed; structural steel; geometry; dimensions.

\section{Introduction}

Gas Metal Arc Welding (GMAW) is widely applied in structural fabrication, ship building and automotive manufacturing. It has high deposition efficiency and can be easily adapted to automation [1]. Growing number of alloys and, consequently, issues with the stability of the arc have often posed major challenges for this process. Carefully chosen welding parameters prevent excessive heat input, thus preventing distortion and other weld defects. [2] It is also important to note that GMAW is still significantly used as manual welding process. Work done by human force is expensive and includes the possibility of making mistakes in the working process. For example, in the ship building industry, it is possible to automate many production processes and thereby increase production intensity and accuracy of products, while decreasing the effect of human factors. [3] Automatization could also mean improvement of working conditions and safety for welders. [4] In the case of pipe spool fabrication, pipe welders need to make instant decisions about oscillation, torch angle, travel speed, and weave amplitude to create high-quality welds. Welders are prone to error and producing repeatable and consistent high-quality welds can be difficult. 
Weld consistency typically deteriorates near the end of a physically demanding 8-hour shift. Given the required repetitive and precise movement of the torch during welding, welder fatigue is an ongoing issue in the industry. Over time, fatigue and repetitive motion often develop into chronic musculoskeletal disorders. But when utilizing a robot, the torch is manipulated by the robot and welder fatigue is reduced dramatically. Welders only monitor the welding process and, if necessary, steer the welding torch or adjust the parameters of the weld process. [5] Innovations in the areas of feedback control, specific current and waveform shape, with highly responsive welding power sources have provided the GMAW process with an ability to adapt to irregularities in the weld zone and have made it possible to effectively regulate key parameters such as current and voltage. That enabled optimization of process performance and lower heat input. The GMAW process development has significantly improved robot welding and enabled combination with other processes, such as laser welding. [2] At the same time, it is necessary to develop reliable heat input control at high production rates achievable through mechanization and use of robots and avoid deterioration of weld quality related to inadequate heat input. The purpose of this study is to present some of already developed models connecting heat input with weld geometry (i.e. weld quality), and to present results of own experimental research conducted using pulsed GMAW process for singlepass fillet weld of structural steels.

\section{Pulsed GMAW}

Pulsed GMAW is a variant of the conventional GMAW welding process in which the current is pulsed. [6] Pulsing was introduced to control metal transfer at low mean current levels by imposing short-duration high-current pulses. Background current can be as low as 15 A. [7] Pulsed GMAW provides additional control of the GMAW process by using a current waveform consisting of a low background level to maintain the arc and a superimposed pulse current to detach drop of filler material (i.e. wire). [2] The cycle illustrates Fig. 1.

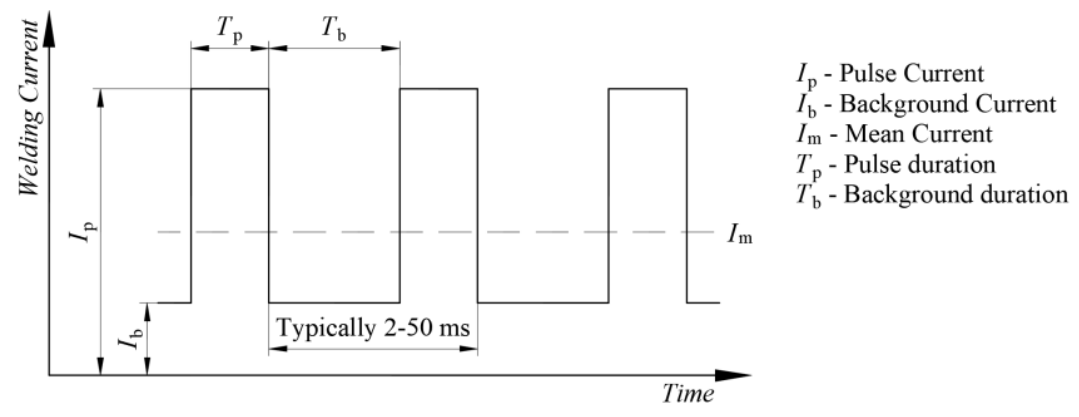

Fig. 1. General principle of pulsed GMAW [6]

Modern welding sets permit the use of a wide range of pulse amplitudes, durations and waveforms at frequencies from a few Hertz to a few hundred Hertz. Pulse amplitude and duration are combined to melt and detach a single droplet of the same diameter as the electrode wire (or slightly smaller). Selection of pulse parameters for a given wire feed speed is a complex operation. Pulse height and duration are a function of wire composition, diameter and, to a lesser extent, shielding gas composition. Pulsing must provide enough heat to melt filler material (wire) and to detach exactly one drop of molten metal per pulse. [8] Generally, advantages of pulsed GMAW welding are [6], [7], [8]:

- It allows the use of smooth, spatter-free welding at mean currents, which would otherwise be too low for all except dip transfer with its irregular transfer and associated spatter.

- Pulsing can extend spray operation below and through the natural transition from dip to spray where globular transfer would normally occur.

- Pulsed transfer is midway between spray transfer and dip transfer mechanism, which can be too 'cold' (due to noncontinuous arcing, the arc effectively 'goes out' between each melting cycle). This makes it ideal for welding of thicker sections where more heat is needed but for which spray transfer is still too 'hot'.

- It allows welding at higher deposition rates for all positions where dip or spray transfer is not applicable.

Pulsed GMAW yields the lowest possible heat input, and most of the issues regarding unnecessarily high heat input are avoided. However, it has also few disadvantages. Production rate (meters of weld per minute) is lower than with dip transfer (i.e. GMAW) due to decrease of wire feed rate as heat input increases, and there are limitations regarding usage of shielding gases in comparison with dip transfer. [8]

State-of-the-art welding equipment integrates electronics and software, and these components allow the process to read the change in the weld area between the workpiece and the torch, and then make corrections to adjust important parameters to ensure optimum results. Modified short circuiting transfer mode processes have been an important research topic in recent decades and have largely proven themselves as stable and efficient processes with lower heat input, even when welding heat sensitive thin sheet sections and dissimilar materials. Research is continuing to extend the applicability of the pulsed process. [2] Since this process uses advanced electronics, it is not economical to use it if cheaper alternatives are available. Different manufacturers of welding equipment use various brand names for pulsed GMAW, but the principle is the same [6]. 


\section{Heat input and weld geometry}

As mentioned before, GMAW is by default mechanised welding process, widely used in various industries. It has great ability to be adapted and used by robots, hence avoiding possible health issues for welders and quality issues for manufacturer. GMAW is heat intensive, causing deformations and residual stress, and it usually requires additional cleaning due to intensive spattering. However, several process variations have been developed, including pulsed one, which significantly reduces heat input and deformations, and virtually eliminates spattering. Combination of pulsed GMAW used by robots is gaining popularity, since it has numerous advantages (and only few disadvantages). It is particularly useful in cases when weld has to be made through several positions without interruption or along complex 3D trajectory. Examples of such single-pass fillet welds are shown in Fig. 2, made by robot using pulsed GMAW on S355 structural steel of various thickness. These welds would be relatively hard to achieve by manual welding.
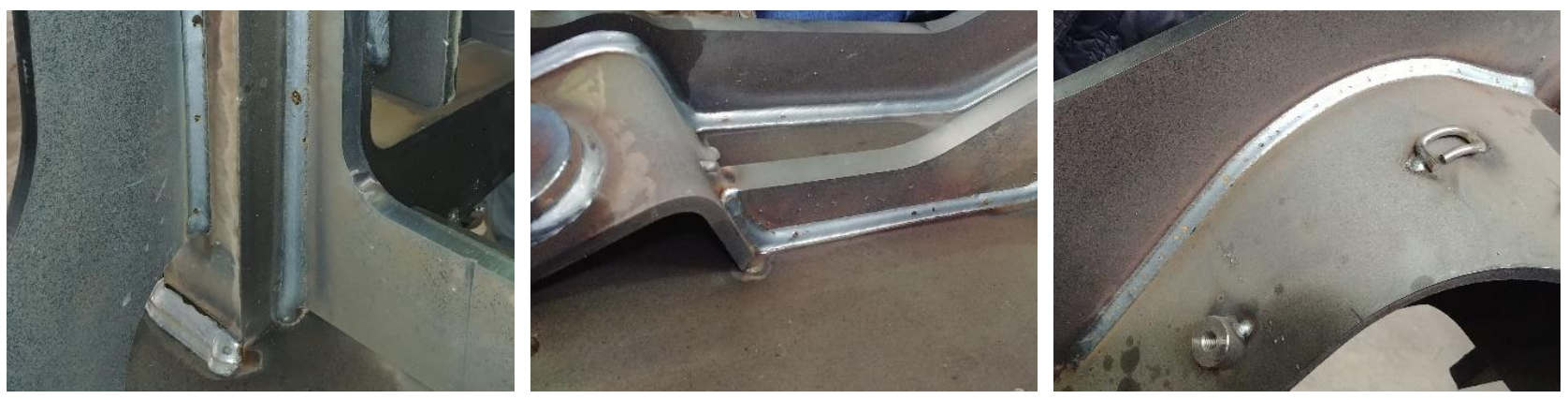

Fig. 2. Examples of fillet welds on S355 structural steel made by robots using pulsed GMAW [9]

To make such demanding welds with quality required by standards and product codes, it is necessary to have not only excellent guidance for welding torch, but accurate correlations between input parameters of welding process and weld geometry. This is particularly important in case weld is stretched along complex three-dimensional line through several welding positions, since different welding parameters are recommended for each welding position. Transitions must be impeccable with geometry and dimensions of weld the same along entire seam.

Each weld is made in accordance with its Welding Procedure Specification (WPS), which is written instruction that specifies all necessary parameters required for certain weld (including pre- and post-weld treatments). Each WPS is supported by Procedure Qualification Record (PQR), which is record of weld tests ensuring that weld will have required properties. With increased weld deposition rate and quality requirements on one side, and tendency to lower welding costs on the other, it is challenging task to develop method for quality assurance of welds. Even though welding according to WPS should guarantee properties described in PQR, seams after welding are regularly examined by one or more NonDestructive Test (NDT) methods, in accordance to respective standards and product codes. However, it would be useful to have real-time method that can be used to preliminarily check weld quality in situ, i.e. immediately after welding. The easiest way to do this is to visually examine welds, checking their geometry and dimensions and comparing them to referent values. Since GMAW does not produce slag, it is relatively easy to use artificial vision (e.g. based on laser) to acquire shape of weld and its dimensions [10]. After comparison of real shape and dimensions with reference ones, realtime adjustment of welding parameters can be made (if necessary).

The key for this, conceptually simple, solution for real-time weld quality control is to have reliable connection between process parameters (i.e. input) and weld shape and dimensions (i.e. output) for certain welding conditions (e.g. base and filler material and position). Size of fillet weld is either calculated or defined by respective product code or standard. It can be described by its leg size $(z, \mathrm{~mm})$ or throat thickness $(a, \mathrm{~mm})$, as shown in Fig. 3 (with z5 taken as an example). Areas of melted filler metal (FM) and base metal (BM) are shown, while effective throat thickness corresponds to the largest inscribed triangle of actual fillet weld, defined with leg sizes $z_{1}$ and $z_{2}$. It is important to select proper set of welding parameters in order to produce fillet welds of required size in everyday production by GMAW. [11]

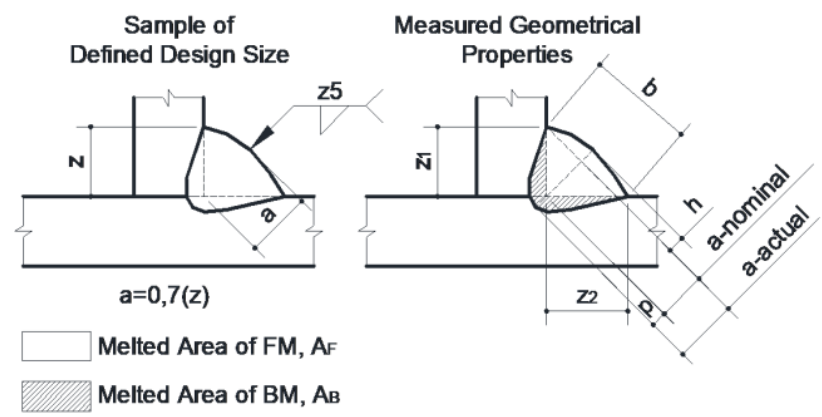

Fig. 3. Geometry and dimensions of fillet welds [11] 
Most influential welding parameters are welding current $(I, \mathrm{~A}), \operatorname{arc}$ voltage $(U, \mathrm{~V})$ and welding speed $(w, \mathrm{~cm} / \mathrm{min})$. These three define important welding parameter, heat input $(Q, \mathrm{~kJ} / \mathrm{mm})$, defined by (1). Here, $\eta$ is heat input efficiency, which generally can be taken as $\eta=0.8$ for conventional GMAW. [11], [12]

$$
Q=\frac{U \cdot I}{w} \cdot \eta
$$

Heat input for pulsed GMAW was calculated according to general recommendation, and it is based on arithmetic mean power for known welding wave current pattern from the used power source (in this case it is Daihen Welbee WBP500L). Calculation is the same as in (1) but using mean (averaged) values of current and arc voltage instead of peak ones. Average heat input efficiency for pulsed GMAW is considered to be the same as for conventional GMAW. [12]

By standardized approach, geometrical properties of fillet welds should be determined with consideration of largest inscribed isosceles triangle (Fig. 3 right), meaning that by using macrographs following can be measured:

- $\quad$ area of melted Base Metal $\left(A_{\mathrm{B}}\right)$,

- $\quad$ area of melted Filler Metal $\left(A_{\mathrm{F}}\right)$,

- throat thickness (nominal and effective, $a$ ),

- leg sizes $\left(z_{1}\right.$ and $\left.z_{2}\right)$,

- $\operatorname{penetration}(p)$,

- reinforcement $(h)$, and

- face width $(b)$.

Dilution $(D, \%)$, which is important geometry parameter of fillet weld, can be calculated by (2). $D$ and $p$ indicate involvement of base metal in effective size of fillet weld. [13] If only the visual evaluation of fillet weld is considered, nominal throat $(a)$, leg sizes $\left(z_{1}\right.$ and $\left.z_{2}\right)$, reinforcement $(h)$ and face width $(b)$ become subject to inspection, with regard to required fillet weld quality level. Only properly prepared macrographs of fillet welds can be used to measure $A_{\mathrm{B}}, A_{\mathrm{F}}$ and $p$ and to calculate dilution $D$ afterwards.

$$
D=\frac{A_{\mathrm{B}}}{A_{\mathrm{B}}+A_{\mathrm{F}}}
$$

In general, weld imperfection tolerances for required quality levels are defined within ISO 5817 [14]. Primary goal of fillet weld inspection and evaluation is comparison of throat size or leg size with required (design) size. Achieved sizes cannot be smaller than designed, while minor larger sizes may be tolerated. Reinforcement $h$ is tolerated within limits regarding the size of fillet weld. Penetration $p$ is always required, but there are no specific limits for its value (generally, increase is desirable and recommended). Dilution $D$ for welding of similar base metals is rather quantitative parameter, while for heterogeneous welding (dissimilar base metals) always presents important quality parameter. [11] All mentioned geometry parameters define quality (therefore strength) of fillet weld, and while some of them can be measured by artificial vision, others can only be calculated. A number of welds would be required to develop and verify model describing relations between input and output, but once that is done, it can be used for real-time weld quality control.

There are numerous researches regarding prediction of geometry and dimensions of weld joints as a function of heat input. [11] However, many of them are related to unconventional welding processes, e.g. electron beam or laser welding and friction welding and its variants. Selection of parameters for conventional (i.e. arc) welding processes still heavily rely on recommendations from base or filler material manufacturer. Additionally, prediction of weld geometry is increasingly harder and more complex in case of multi-pass welds. Possibility to control single-pass weld geometry by controlling process parameters just recently got attention. Since pulsed GMAW is relatively new variant of this process, a limited number of articles regarding geometry prediction have been published. Additional general problem with pulsed processes is calculation of heat input. Nevertheless, it has been shown that (1) gives sufficiently accurate heat input calculation in case proper parameters are taken into consideration. [11], [15]

One of the oldest and simplest relations between heat input $Q$ in $\mathrm{kJ} / \mathrm{mm}$ and leg size $z$ in millimetres is given by (3) [16]. This model is applicable to all single-pass conventional arc welding processes and, conditionally, pulsed variant.

$$
z=5.5 \sqrt{Q}
$$

Other models and approaches are often more comprehensive, and details can be obtained in respective references. In most cases, relations between input and output are described by using basic or advanced statistical analysis, while sometimes relations are supported by FEM or other computational tools. It has been shown that by combining a numerical thermo-fluid model with an appropriate genetic algorithm based optimization scheme would be possible to obtain required weld size using various combinations of welding parameters, in which the most influential parameter is welding current I. [17] It has been demonstrated that is possible to predict weld bead geometry and even width of Heat Affected Zone (HAZ) by monitoring principal welding parameters $(I, U$, and $w)$ and analysing weld pool width with high-speed camera. This required quite sophisticated approach and complex quadratic model. [18] 
There is also model developed for predicting weld geometry as function of $I$ and $U$ by using multivariate regressive curvilinear analysis. [13] One approach used model based on power function analysis of influence of heat input on geometry, but only for case of welding in overhead position. [1] One research performed study of heat input Q and welding position on achieved fillet weld size a and, furthermore, on weld strength. [19] There are researches that have not provided exact relations between welding parameters and weld geometry but rather demonstrated existence of their mutual influences. [2] Some considered additional parameters (e.g. wire feed rate, torch angle and nozzle-to-plate distance) [20], or usage of cored instead of solid wire [21]. Researches regarding pulsed GMAW usually offer more complex relations between process parameters and weld geometry, since process itself is more complex. [22], [23], [24], [25] Since parameters directly influence metal transfer mode, and each has distinctive sound, it has been suggested to use that for control of welding process. [26], [27]

\section{Experiment}

All abovementioned researches and published papers offer relations between process parameters (i.e. heat input) and weld geometry for strictly defined welding conditions. The reason for such approach is complexity of welding process, which involves melting, solidification, and microstructural changes. To achieve welding process control according to idea presented earlier in paper, it is necessary to make large number of welds in variety of conditions and develop and verify relationship model connecting welding parameters and welding geometry.

To evaluate influence of heat input on weld geometry, a series of fillet welds of $6 \mathrm{~mm}$ thick plates of structural steel S235JR (EN 10025-2) has been made using pulsed GMAW. This steel is unalloyed, with chemical composition given in Table 1 and mechanical properties given in Table 2 . It has been chosen as it is widely used due to good weldability and low price, while this thickness has been chosen since it still can be used for single-pass fillet welds. Power source used in experiment is digitally controlled Daihen Welbee WB-P500L.

\begin{tabular}{|l|c|c|c|c|c|c|c|c|}
\hline Element & $\mathbf{C}$ & Si & Mn & P & S & N & Cu & Al \\
\hline$\%$ & 0.140 & 0.010 & 0.080 & 0.025 & 0.015 & 0.010 & 0.200 & 0.080 \\
\hline
\end{tabular}

Table 1. Chemical composition of S235JR structural steel [28]

\begin{tabular}{|c|c|c|c|}
\hline Yield strength & Tensile strength & Elongation A5 & Impact toughness \\
\hline $\min .235 \mathrm{MPa}$ & $360-510 \mathrm{MPa}$ & $\min .26 \%$ & $27 \mathrm{~J}$ at $20^{\circ} \mathrm{C}$ \\
\hline
\end{tabular}

Table 2. Mechanical properties of S235JR structural steel [28]

Only two positions were considered, flat (PB) and overhead (PD), since they can be considered as extreme ones, while all others could fit in between. Heat input is calculated according to (1), using averaged values measured by welding device. Welding parameters were chosen to represent relatively limited heat input range, given in Table 3. In this research, parameters were kept within recommended range (limited) by device's control system, since it does not allow to go out of pre-programmed range valid for selected base material and welding process. Pulsed GMAW is generally sensitive regarding parameters selection, and minor deviation in values of $I$ and $U$ can lead to unsatisfactory welds.

\begin{tabular}{|c|c|c|c|c|}
\cline { 2 - 5 } \multicolumn{1}{c|}{} & Welding current (A) & Arc voltage (V) & Welding speed (mm/s) & Heat input (kJ/mm) \\
\hline PB & $200-300$ & $21-26$ & $3.60-7.20$ & $0.39-0.78$ \\
\hline PD & $160-260$ & $20-25$ & $3.50-4.90$ & $0.43-1.39$ \\
\hline
\end{tabular}

Table 3. Welding parameters used in experiment

Filler metal used for welding was solid wire G 424 M21 3Si1 (EN ISO 14341-A), with 1.2 mm diameter. Shielding gas in all experiments was mixture of $82 \%$ Ar and $18 \%$ of $\mathrm{CO}_{2}$, with flow of $17 \mathrm{l} / \mathrm{min}$. This is recommended usually mixture for this kind of welding of structural steel. Contact Tip to Workplace Distance (CTWD) was kept between 12 and $15 \mathrm{~mm}$. All welded samples were visually examined after welding. Weld legs were measured $\left(z_{1}\right.$ and $\left.z_{2}\right)$, as well as actual throat thickness $\left(a_{\mathrm{a}}\right)$. Based on this, achieved quality level is determined for the purpose of the further study, graded from "B" to "D" as per ISO 5817. Reinforcement $h$ was also measured, because of particularly high values achieved in overhead position. Furthermore, middle sections of fillet welds were cut, grinded, polished and etched with nital for macrograph examination as per ISO 17639.

Some of geometrical parameters of fillet welds were measured using prepared macrographs, while others were calculated. This includes nominal throat thickness $a_{\mathrm{n}}$, penetration $p$, reinforcement $h$ and dilution $D$ (based on $A_{\mathrm{B}}$ and $A_{\mathrm{F}}$ as shown in Fig. 3), as well as leg sizes $\left(z_{1}\right.$ and $\left.z_{2}\right)$ and effective throat thickness $a_{\mathrm{e}}$ (consequence of fillet weld asymmetry, i.e. variable and unequal $z_{1}$ and $z_{2}$ ). All measures were taken indirectly, using photos of macrographs in AutoCAD in scale 1:1. Samples of examined and analysed macrographs are shown in Fig. 4, where white lines are inscribed deliberately to precisely express weld cross-section geometry. 


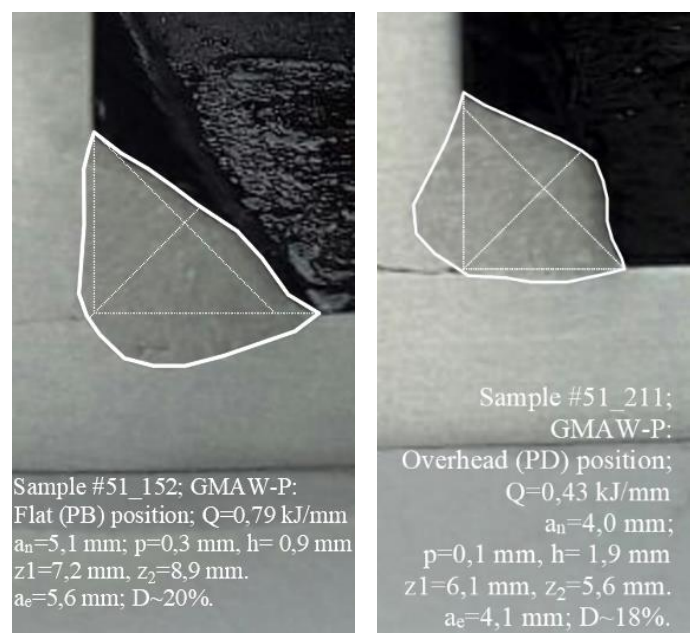

Fig. 4. Samples of fillet welds made in flat (PB, left) and overhead (PD, right) position

Successfully made welds (one per set of parameters) have been also used for analysis of weld profile along seam. Welded samples have been visually checked for consistency of shape. Afterwards, ten perpendicular cuts were made for each weld, and their profiles compared.

\section{Results and discussion}

General conclusion from experiment, based on observations during welding, visual examination of welds and macrograph evaluation, show that pulsed GMAW requires lower heat input for the same size of fillet weld in comparison to GMAW. Minor spattering was observed, while face contour and shape were visually more uniform, compared with GMAW. It is also possible to conclude that higher reinforcement is always present in overhead fillet joints. This is obviously consequence of gravity effect on the weld pool.

Typical samples of macrographs of examined fillet welds are shown in Fig. 4. Information regarding used heat input, welding position (PB or PD) and measured geometrical parameters are given as well. Thick solid lines represent the contour of melted metal (i.e. weld metal), while thin doted lines represent edges of base metals, largest inscribed isosceles triangle, and throat thickness line, respectively.

All measured geometrical parameters were evaluated and analysed by the mean of simple linear regression analysis, according to the model given by (3), (labelled as "acc. to (3)"). As this model relates leg size $z$ for known heat input $Q$, similar relation is assumed for other geometrical parameters. Assumption is possible because all geometry parameters (dimensions) are strongly connected and mutually related. Fillet weld size represented as throat thickness $a$ is generally used approach in Europe, while leg size $z$ is more common in USA.

Fig. 5 shows size of effective throat thickness $a_{\mathrm{e}}$ as function of heat input $Q$, generally, for both welding positions. As possible to see, pulsed GMAW gives up to $40 \%$ larger weld sizes in comparison to model described by (3). There are several possible explanations for this. One of them is way how heat input is calculated for pulsed GMAW, since the simplest model has been used, described with (1), but with averaged parameters. Relation of $Q$ and $z$ described with (3) is the simplest as well, without sufficient details regarding heat input ranges and process parameter limitations.

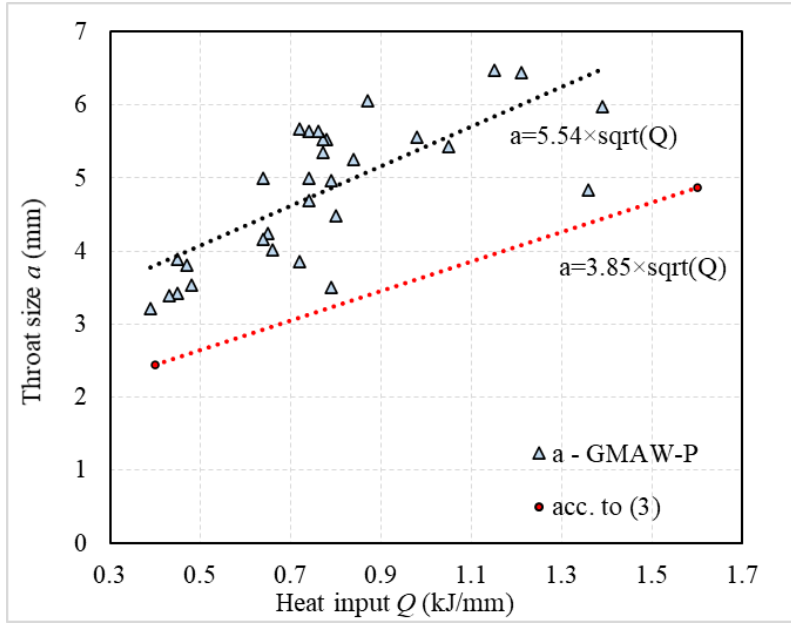

Fig. 5. Throat size of fillet weld as function of heat input for pulsed GMAW 
As possible to see in Fig. 5, throat size has significant scattering, and, consequently, used model has low reliability. Reason could be insufficient number of welds, but more probable reason is usage of simplified model of calculation of heat input, based on average values of current and voltage. Also, model describing relation of heat input and weld size is simplest possible, giving significant disagreement of weld size predicted according to (3) and measured values.

Fig. 6 shows dependence of penetration $p$, reinforcement $h$ and dilution $D$ on used heat input $Q$ for two welding positions. General range for penetration is $0.1-0.8 \mathrm{~mm}$ (with peak at $2.2 \mathrm{~mm}$ ), for reinforcement $1.3-4.0 \mathrm{~mm}$, and for dilution 6-41\%. Existence of such ranges is consequence of manual welding. As mentioned before, producing repeatable and consistent high-quality welds can be difficult in case of manual welding. Despite best efforts of well-trained welder, it is hard to maintain constant CTWD and torch angles, even though pulsed GMAW is used. This is particularly hard in overhead position.
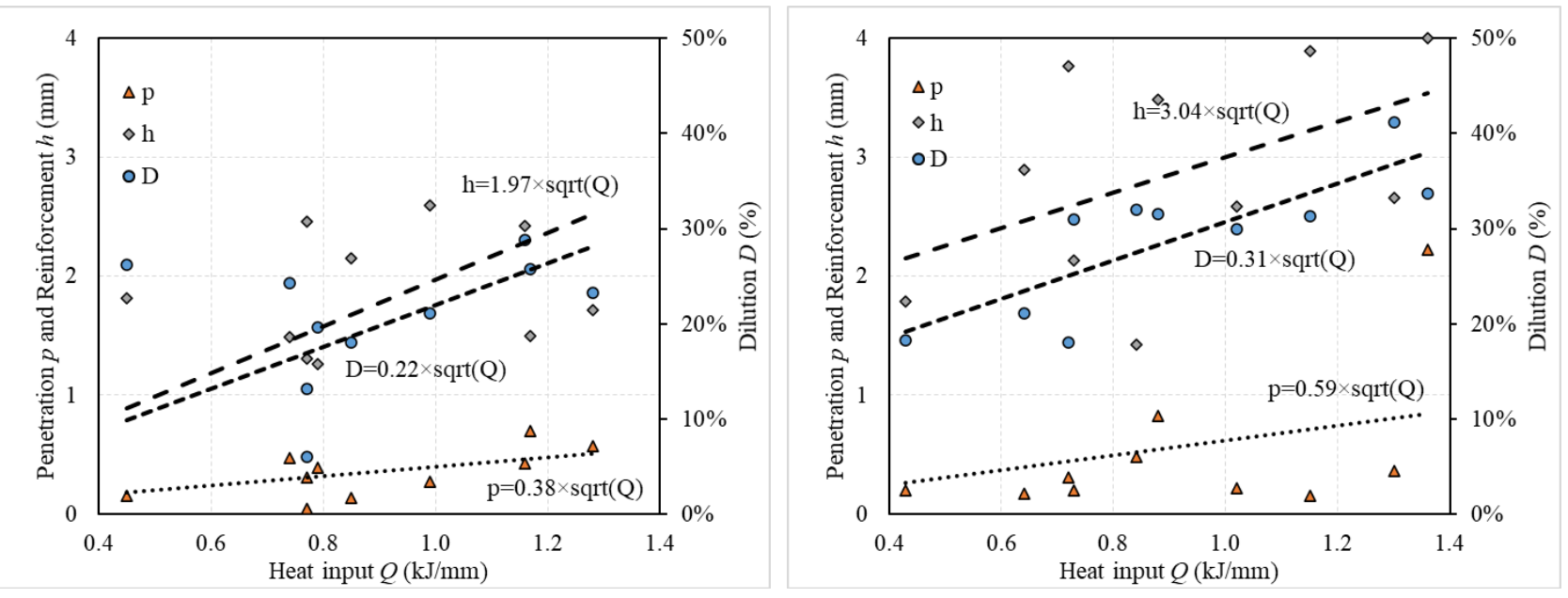

Fig. 6. Penetration, reinforcement and dilution as function of heat input for flat (left) and overhead (right) position

The principal difference between welds shown in Fig. 6 is welding position (two extremes are used in experiment). Regarding general range of the penetration $p(0.1-0.8 \mathrm{~mm}$, with extreme of $2.2 \mathrm{~mm}$ neglected), it can be concluded that slightly higher $p$ can be achieved in overhead position, what is beneficial to the final strength of a fillet weld. Overhead position provides in average $54 \%$ higher reinforcement in comparison to flat welding position. Generally, when welding homogenous base metals, dilution $D$ can increase strength of the fillet weld, in a similar manner as penetration $p$. Therefore, higher values of $D$ are desirable, and it has been shown that they are achieved in overhead position (approximately $40 \%$ higher in comparison to flat).

Additionally, weld profile along the seam has been analysed for both positions and for all successfully made welds. After visual check for spattering, crates and visible inclusions, ten cuts were made per weld (every $15 \mathrm{~mm}$ along seam), and weld profiles compared. It has been shown that weld profile is uniform, without significant deviations, even though it is made by manual welding. However, it is important to mention that this was rather qualitative examination, where no measures have been taken to quantify differences.

\section{Conclusion}

GMAW welding is widely used welding process, since it has hight deposition rate and can be easily automated or robotised. Many variants have been developed, leading to further advances in application. One of the most important is pulsed, which enables lower heat input and higher productivity. Pulsed GMAW is convenient to be used with robots, since it does not require additional weld cleaning or grinding. Moreover, it is relatively easy to incorporate artificial vision (e.g. based on laser) to visually check welds and measure its dimensions in-situ in real time. That increases productivity and quality, while lowering weld costs. To implement this, it is necessary to develop model that reliably connects input parameters (current, voltage and welding speed, i.e. heat input) with output (weld geometry and dimensions). In that way, parameters could be adjusted instantaneously during welding, enabling same weld profile along seam with complex geometry and through various welding positions.

This paper gives brief overview of researches regarding models of geometry prediction of pulsed GMAW single-pass fillet welds of structural steels. Also, an experimental study has been conducted to verify existing and propose new relations between input and output. Several fillet welds have been made in two extreme positions, flat and overhead, by using pulsed GMAW on $6 \mathrm{~mm}$ thick sheets of S235JR structural steel. It has been shown that heat input and welding position strongly influence the geometry and dimensions of fillet welds. New relations for penetration $p$, reinforcement $h$ and dilution $D$ have been proposed, based on existing simple model for leg size $z$. Simplified approach has been also used for calculation of heat input, using mean values of current and voltage measured during welding. Such approach gave significant scattering of results, making this model unusable for control of robotized welding process. 


\section{Further research}

Further research should use more accurate (and therefore complex) model for calculation of heat input for pulsed GMAW, which will consider full current and voltage profiles instead of mean values. Dimensions should be predicted and related with input parameters more accurately, what could be also achieved by using more complex models. Interesting possibilities include prediction of geometry for multi-pass welds and transitions from one to another welding position. Such models, fully verified and coupled with quality assurance supported with PQR and WPS, could lead to fully robotised welding. Particularly, it could be interesting to develop models for higher classes of structural steels (e.g. 355 and 460) due to more strict cooling conditions.

\section{References}

[1] Yaakub, M. Y., Tham, G., Rahim, W. M. A. W. A., Radzi, M. A. R. M. \& Mahmud, A. (2013). Prediction of Welding Parameters and Weld Bead Geometry for GMAW Process in Overhead T-Fillet Welding Position(4F), Advanced Materials Research, Vol. 686, 2018, pp. 320-324., ISSN 1662-8985, DOI: 10.4028/www.scientific.net/AMR.686.320

[2] Mvola, B., Kah, P., Martikainen, J. \& Hiltunen, E. (2013). Applications and benefits of adaptive pulsed GMAW, Mechanika, Vol. 19, No. 6, 2013, pp. 694-701., ISSN 1392-1207, DOI: 10.5755/j01.mech.19.6.6003

[3] Czifra, J., Vicikova, J. \& Szabo, P. (2010). Automated production system for pipelines of vessels. Proceedings of the 21st International DAAAM Symposium, B. Katalinic (Ed.), Vol. 21, No. 1, ISSN 1726-9679

[4] Popescu, M. (2010). Welding Ergonomics - Elements. Proceedings of the 21st International DAAAM Symposium, B. Katalinic (Ed.), Vol. 21, No. 1, ISSN 1726-9679

[5] Karimzadeh, S. (2019). The Need for Artificial Intelligence in the Age of Industry 4.0, Welding journal, Vol. 98, No. 5, 2019, pp. 34-35., ISSN 0043-2296

[6] Horvat, M. \& Kondić, V. (2012). The examples of modified procedures of MIG/MAG welding, Tehnički glasnik, Vol. 6, No. 2, 2012, pp. 137-140., ISSN 1864-6168

[7] Brown, E. (2017). An Introduction to Pulsed GMAW, Welding Journal, Vol. 96, No. 2, 2017, pp. 76-78., ISSN 0043-2296

[8] Tasic, P.; Hajro, I. \& Hodzic, D. (2017). Technological and Economical Aspects of Arc Welding of Al 5754, Proceedings of the 28th DAAAM International Symposium, pp.854-858, B. Katalinic (Ed.), Published by DAAAM International, ISBN 978-3-902734-11-2, ISSN 1726-9679, DOI: 10.2507/28th.daaam.proceedings.119

[9] Private archive

[10] Reddy, G. A., Raman A., Reddy H. \& Kumar G. S. (2008). Laser Vision Based Seam Tracking System for Welding Automation, Proceedings of the 2008 International Conference on Image Processing, Computer Vision, \& Pattern Recognition, July 14-17, 2008, Las Vegas Nevada, USA

[11] Hajro, I. \& Tasic, P. (2020). Influence of heat input and welding position on geometrical properties of GMAW fillet welds of unalloyed steel, TEM Journal, Vol. 9, No. 2, 2020, pp. 496-500., ISSN 2217-8309, DOI: 10.18421/TEM9210

[12] Bosworth, M. R. (1991), Effective Heat Input in Pulsed Current Gas Metal Arc Welding with Solid Wire Electrodes, Welding Journal, Supplement, 1991, pp. 111-117

[13] Ribeiro, R. A., Santos, E. B. F., Assunção, P. D. C., Maciel, R. R. \& Braga E. M. (2015). Predicting Weld Bead Geometry in the Novel CWGMAW Process, Welding Journal, Vol. 94, No. 9, 2015, pp. 301-311., ISSN $0043-2296$

[14] ISO 5817:2014, Fusion-welded joints in steel, nickel, titanium and their alloys (beam welding excluded) - Quality levels for imperfections, International Organization for Standardization

[15] Joseph, A., Harwig, D. D., Farson, D. \& Richardson, R. (2003). Assessing the effects of GMAW-P parameters on arc power and weld heat input, Proceedings of 6th International conference Trends in Welding Research, 2002

[16] Miller, D. K. \& Funderburk R. S.(2001). Tools for reviewing Welding Procedures, Welding Journal, Vol. 80, No. 7, 2001, pp. 40-43., ISSN 0043-2296

[17] Kumar, A. \& DebRoy, T. (2005). Transport phenomena and genetic algorithm based window of welding variables to achieve a target gas metal arc fillet weld geometry, Proceedings of 7 th International conference Trends in Welding Research, 2005

[18] Lima, E. J., Castro, C., Bracarense, A. Q. \& Campos M. M. (2005). Development of a model to predict weld bead geometry during the GMAW process using high speed camera. Proceedings of 7 th International conference Trends in Welding Research, 2005

[19] Sugitani, D. \& Mochizuki, M. (2013). Experimental Study on Effects of Root Gap and Fillet Size of Welds on Joint Strength, Quarterly Journal of the Japan Welding Society, Vol. 31, No. 4, 2013, pp. 104-108.

[20] Kolahan, F. \& Heidari, M. (2009). A New Approach for Predicting and Optimizing Weld Bead Geometry in GMAW, Intl. J. Of Mechanical and Mechatronics Engineering, Vol. 3, No. 11, 2009, pp. 1391-1394.

[21] Gucwa, M. \& Beczkowski, R. (2014). The Effect of Heat Input on the Geometric Properties of Welded Joints, Archivess of Foundry Engineering, Vol. 14, 2014, pp. 127-130., ISSN 1897-3310 
[22] Sen, M., Mukherjee, M. \& Pal, T. K. (2014). Prediction of Weld Bead Geometry for Double Pulse Gas Metal Arc Welding Process by Regression Analysis, Proceedings of 5th International Manufacturing Technology, Design and Research Conference, December 12th-14th, 2014, IIT Guwahati, Assam, India

[23] Yao, P., Zhou, K. \& Huang, S. (2019). Process and Parameter Optimization of the Double-Pulsed GMAW Process, Metals, Vol. 9, No. 9, 2019, DOI: 10.3390/met9091009

[24] Zhai, P., Xue, S., Wang, J., Tao, Y., Chen, W., Chen, T. \& Ji, S. (2020). Comparative Study of Droplet Transfer Modes on Appearance, Microstructure, and Mechanical Properties of Weld during Pulsed GMAW, Metals, Vol. 10, No. 5, 2020, DOI: 10.3390/met10050611

[25] Zhai, P., Xue, S., Wang, J., Chen, W., Chen, T. \& Ji, S. (2020). Effects of Arc Length Adjustment on Weld Bead Formation and Droplet Transfer in Pulsed GMAW Based on Datum Current Time, Metals, Vol. 10, No. 5, 2020, DOI: $10.3390 /$ met10050665

[26] Horvat, J., Prezelj, J., Polajnar, I. \& Čudina, M. (2011). Monitoring Gas Metal Arc Welding Process by Using Audible Sound Signal, Journal of Mechanical Engineering, Vol. 57, No. 3, 2011, pp. 267-278., DOI: 10.5545/svjme.2010.181

[27] Cayo, E. H. \& Absi, S. C. A. (2008). Welding Quality Measurement Based on Acoustic Sensing, ABCM Symposium Series in Mechatronics, Vol. 3, 2008, pp. 571-579.

[28] ThyssenKrupp, precidur ${ }^{\circledR}$ S235 JR/J0/J2, steel specification, version 8/19 